\title{
Validation of organoleptics and instrumental measurement for halitosis among patient with malodour
}

\begin{abstract}
Objective: Assess the severity/levels of halitosis among the patient with malodor by using organoleptic technique and to compare the halitosis by organoleptics measurement and halitosis instrument/bad breath tester $\left(\operatorname{Tanita}^{\circ}\right)$.

Materials and methods: A total 320 study population was considered for study and the age ranged from 20-60 years. Halitosis is measured by organoleptic method by two different examiner and also used halitosis instrument/bad breath tester $\left(\operatorname{Tanita}^{\circ}\right)$ with scoring criteria. For data collection preformed, closed ended Questionnaire was used...Statistical analyses were used: chi square test.
\end{abstract}

Result: Out of 320, $29(0.09 \%)$ subjets was recorded with no halitosis. While comparing of data of organoleptic method and instrument/bad breath tester $\left(\right.$ Tanita $\left.^{\circ}\right)$ sensitivity and specificity are $41.1 \%$ and $53.3 \%$ respectively.ROC curve is 0.473

Conclusion: The organoleptic method is more effective as compared halitosis instrument for detection of halitosis

Keywords: halitosis, organoleptic method, halitosis instrument(Tanita)
Volume II Issue I - 2020

\author{
Ashwini Dayma, ${ }^{\prime}$ Manish Jain, ${ }^{2}$ Vrinda \\ Saxena, ${ }^{3}$ Nilesh Torwane, ${ }^{4}$ Vineesh Vishnu, ${ }^{5}$ \\ Anshika Khare ${ }^{6}$ \\ 'Department of Community \& Preventive Dentistry, UCMS \\ college of Dental Surgery, Nepal \\ ${ }^{2}$ Department of Community \& Preventive Dentistry, SMBT \\ Dental College, India \\ ${ }^{3}$ Department of Community \& Preventive Dentistry, Govt. \\ Dental College, India \\ ${ }^{4}$ Department of Community \& Preventive Dentistry, Saraswati \\ Dhanwantri Dental College, India \\ ${ }^{5}$ Department of Community \& Preventive Dentistry, Peoples \\ Dental Acadmey, India \\ ${ }^{6}$ Department of Community \& Preventive Dentistry, Peoples \\ College of Dental Science, India
}

Correspondence: Ashwini Dayma, Department of Community \& Preventive Dentistry, UCMS College of Dental Surgery, Nepal, Email ashwinidayma@gmail.com

Received: January 08, 2020 | Published: January 27, 2020

\section{Introduction}

India, sixth biggest country by area is the second most populous country. Factors contributing to the steady rise in prevalence of oral disease due to poor oral health awareness. Annual health budget is $2 \%$ of Gross National Product but no specific budget is earmarked for oral health. ${ }^{1}$

Oral Diseases are a major public health concern owing to their higher prevalence and their effects on the individual's quality of life. ${ }^{2}$ According to the World Health Organization (WHO), "Promotion of oral health is a cost-effective strategy to reduce the burden of oral disease and maintain oral health and quality of life." ${ }^{3}$

A large ratio of these diseases can be prevented at individual and community levels by providing oral health-related education; thus, improving the oral health attitude and practices among the general population. ${ }^{4}$ For example; proper brushing is essential for cleaning teeth and gums effectively. Preventive dental care is almost nonexistent in the rural areas and very limited in the urban areas of India. $^{5}$

Oral malodour (also known as bad breath, halitosis, fetor ex ore) usually originates when the halitosis emitted through the mouth combines with malodourous compounds originating in the oral cavity. So many reasons behind halitosis bad breath can be caused by following

1. Poor dental hygiene - Infrequent or improper brushing and flossing, allows bits of food that are stuck between the teeth to decay inside the mouth. Poor oral hygiene eventually will lead to periodontal (gum) disease, which also can cause bad breath.
2. Infections in the mouth - these can be caused by either a cavity in a tooth or by periodontal (gum) disease.

3. Respiratory tract infections - Throat, sinus or lung infections.

4. External source - Garlic, onions, coffee, cigarette smoking, and chewing tobacco. Smoking and drinking coffee, tea and/or red wine will contribute to your teeth becoming discoloured.

5. Dry mouth (xerostomia) - this can be caused by salivary gland problems, medicines or "mouth breathing." A large number of prescriptions and over the counter medicines cause dry mouth.

6. Illnesses - Diabetes, liver disease, kidney disease, lung disease, sinus disease, reflux disease and others.

7. Psychiatric illness - some people may believe they have bad breath, but others do not notice it. This is referred to as "pseudohalitosis."

Bad breath has a significant impact on our daily social life to those who suffer from it. Oral malodour may rank only behind dental caries and periodontal disease as the cause of patient's visit to the dentist. ${ }^{6}$ This malodour causing volatile sulphur compounds result from microbial fermentation of proteins, peptides and mucins found in saliva, blood, postnasal drip, gingival crevicular fluid, lysed neutrophils and desquamated epithelial cells. ${ }^{7}$ Many studies have demonstrated that hydrogen sulphide (HS), methyl mercaptan $\left(\mathrm{CH}_{2} \mathrm{SH}\right)$ and to a lesser extent, dimethyl sulphide $\left(\mathrm{CH}_{3} \mathrm{SCH}\right)$ accounts $90 \%$ of the total volatile sulphur compounds (VSCs) found in the mouth air, suggesting that these volatile sulphur compounds are the chemicals responsible for halitosis. ${ }^{8}$ In this present period of 
evidence-based dentistry and oral health, foremost priority should be given to researches dealing to validate organoleptics and instrumental measurement of halitosis among patient with malodor.

\section{Materials \& methods}

This was a descriptive cross sectional study which included 320 halitosis patients reporting in the satellite center of dept. of public health dentistry, peoples dental academy, Bhopal Examination was done for period of three months \& age-group between 20-60 with the chief complain of bad breath.. Ethical clearance was obtained from the Institutional Ethical Committee. A written informed consent was obtained from the patients prior to the inclusion in the study. All the patients are included who were reporting to the department with the chief complain of malodour in six month time \& excluded are Individuals with self-reporting systemic diseases affecting breath odor such as uremia, hepatic cirrhosis, diabetes mellitus (Type 1), and Sinusitis. Treatment with antibiotics in the past three weeks, and the consumption of onions or garlic in the past two days. On the day of the examination, the participants were told not to consume alcohol, nicotine, or products containing mint. Prior to measurement, each participant had to subjectively assess the intensity of his/her own oral odor. Double investigator was trained and calibrated for carrying out the investigations for the entire study duration. Training and calibration was done in the Department of Public Health Dentistry, People's Dental Academy, Bhopal. A total 10 patients were examined for the questionnaire validity and assessed of the halitosis.

A checklist of questions will be used to collect the preliminary information from all the eligible participants who have consented. The check list will be filled by the examiner himself in a face to face interview to ensure uniformity in data collection and to avoid misinterpretation of the questions. Halitosis will be measured by following two techniques.

1. Organoleptics method.

\section{Bad Breather Tester $\left(\right.$ TANITA $\left.^{\circ}\right)$.}

The organoleptic test was conducted using a screen which concealed the judge from the individuals and a sterile glass tube (10 $\mathrm{cm}$ in length and $2 \mathrm{~cm}$ in diameter), which was fitted into a hole in the screen. Each volunteer was requested to close his/her mouth for one to two minutes prior to sampling and place about $4 \mathrm{~cm}$ of the glass tube into his/her mouth, then slowly exhale his/her mouth breath through the glass tube. This step was repeated three times during each test. One judge at a time smelled the mouth odour of the individuals until all three judges had evaluated the subjects. Organoleptic scores were then recorded independently by each judge on an ordinal scale as follows:

\section{0 -No malodor 1-Slight malodour 2-moderate oral malodour}

3: Strong malodor (strong intensity of mouth odor with entirely unacceptable)

\section{3. very strong oral maodor}

The recording of malodour (halitosis) was done using a small hand held breath checking device, which detected the volatile sulphur compounds and hydrocarbon gases in mouth air. As the monitor number appear was turned on, it emitted a beep, odour levels were measured by one of the grading on the graphic display of the instrument. if ' $E$ ' appeared then it was considered a reading error and the procedure was repeated. The organoleptics analysis was used to select the patient and it will be compared with the small poratable Sulphide monitor $\left(\right.$ TANITA $^{\odot}$ Breath Checker)

\section{0 -No malodor 1-Slight malodour 2-moderate oral malodour}

3: Strong malodor (strong intensity of mouth odor with entirely unacceptable)

4. very strong oral maodor

\section{5. extremely strong}

The data was entered onto a personal computer and statistical analysis was done using SPSS version 20 [IBM Pvt Ltd, Chicago, IL, USA] using the relevant statistical tests in consultation with a statistician. Chi-square test is used to compare the groups.

\section{Result}

The demographic distribution of study subjects according to age $\&$ gender. There were 320 patient reported , out of which maximum patient reported in the age group between 20-30 year \& minimum reported in the age group of above 50 year. Highly Statistically significant result were found between age \& gender (Table 1). The distribution of organoleptics score with gender which include no malodor, slight malodor, moderate malodor, severe malodor, strong malodor it shown significant result (Table 2). The distribution of oral hygine practice with organoleptics score \& halitosis score which include cleaning aid, material used \& brushing technique with both the score. When compare with organoleptic score with score it shown statistically highly significant result in all aspects (Table 3).The sensitivity \& specificity of organoleptics score with TANITA for the detection of the halitosis. Sensitivity \& specificity was only $41.4 \%$ $\& 53.3 \%$ respectively in the measurement of halitosis. ROC Curve area is 0.473 . Halitosis measurement by TANITA is not significantly associated with organoleptics score $(\mathrm{P}=0.634)$ (Table 5$)$. The validity $\&$ reliability of organoleptics score \& tanita. chronbach alpha was 0.24 and it shown moderate agreement (Table 6).

Table I Demographic distribution of study subject according to age \& gender

\begin{tabular}{lllll}
\hline $\begin{array}{l}\text { Age Groups } \\
\text { (Year) }\end{array}$ & Male & Female & $\begin{array}{l}\text { Chi- } \\
\text { square }\end{array}$ & p-value \\
\hline $20-30$ & $87(60 \%)$ & $58(40 \%)$ & 17.733 & $0.001(\mathrm{HS})$ \\
$31-40$ & $33(43.4 \%)$ & $43(56.6 \%)$ & & \\
$41-50$ & $31(57.4 \%)$ & $23(43.6 \%)$ & & \\
More than 50 & $37(82.2 \%)$ & $8(17.8 \%)$ & \\
\hline
\end{tabular}

Table 2 Distribution of organoleptics score with gender

\begin{tabular}{|c|c|c|c|c|}
\hline $\begin{array}{l}\text { Organoleptics } \\
\text { score }\end{array}$ & Male & Female & $\begin{array}{l}\text { Chi-square } \\
\text { test }\end{array}$ & p-value \\
\hline No Malodor & $18(62.1 \%)$ & II(37.9\%) & 9.91 & $0.04(\mathrm{~S})$ \\
\hline Slight Malodor & $17(8 \mid \%)$ & $4(19 \%)$ & & \\
\hline $\begin{array}{l}\text { Moderate } \\
\text { malodor }\end{array}$ & $88(62.4 \%)$ & $53(37.6 \%)$ & & \\
\hline Severe Malodor & $45(53.6 \%)$ & $39(46.4 \%)$ & & \\
\hline Strong Malodor & $20(44.4 \%)$ & $25(55.6 \%)$ & & \\
\hline Total & $188(58.5 \%)$ & $\mid 32(4 \mid .25 \%)$ & & \\
\hline
\end{tabular}


Table 3 Distribution of the oral hygine practice with organoleptics score \& halitosis score

\begin{tabular}{|c|c|c|c|c|c|c|c|c|}
\hline & & \multicolumn{4}{|c|}{ Organoleptic score } & \multicolumn{3}{|c|}{ Score } \\
\hline & & $\begin{array}{l}\text { No } \\
\text { malodor }\end{array}$ & $\begin{array}{l}\text { Slight } \\
\text { malodor }\end{array}$ & $\begin{array}{l}\text { Moderate } \\
\text { malodor }\end{array}$ & $\begin{array}{l}\text { Severe } \\
\text { malodor }\end{array}$ & $\begin{array}{l}\text { Strong } \\
\text { malodor }\end{array}$ & Absent & present \\
\hline \multirow{3}{*}{$\begin{array}{l}\text { Cleaning } \\
\text { by }\end{array}$} & Toothbrush & $29(14.5 \%)$ & I4(7\%) & $80(40 \%)$ & $45(22.5 \%)$ & $32(15 \%)$ & $29(\mid 4.5 \%)$ & $|7|(85.5 \%)$ \\
\hline & Finger & $0(0 \%)$ & $7(8.3 \%)$ & $33(39.3 \%)$ & $39(46.4 \%)$ & $5(6 \%)$ & $0(0 \%)$ & $84(100 \%)$ \\
\hline & Neemsticks & $0(0 \%)$ & $0(0 \%)$ & $28(77.8 \%)$ & $0(0 \%)$ & $8(22.2 \%)$ & $0(0 \%)$ & $36(100 \%)$ \\
\hline \multicolumn{2}{|c|}{ Chi-square test } & 60.41 & & & & & 19.13 & \\
\hline \multicolumn{2}{|l|}{ p-value } & $0.001(H . S)$ & & & & & $0.00 \mathrm{I}(\mathrm{H} . \mathrm{S})$ & \\
\hline \multirow{4}{*}{$\begin{array}{l}\text { Material } \\
\text { used }\end{array}$} & Toothpaste & $29(10.5 \%)$ & $21(7.6 \%)$ & II3(40.9\%) & $80(29 \%)$ & $0(0 \%)$ & $29(10.5 \%)$ & $247(89.5 \%)$ \\
\hline & Charcoal & $0(0 \%)$ & $0(0 \%)$ & $0(0 \%)$ & $4(50 \%)$ & $0(0 \%)$ & $0(0 \%)$ & $8(100 \%)$ \\
\hline & Brick & $0(0 \%)$ & $0(0 \%)$ & $0(0 \%)$ & $0(0 \%)$ & $0(0 \%)$ & $0(0 \%)$ & $0(0 \%)$ \\
\hline & Other & $0(0 \%)$ & $0(0 \%)$ & $28(77.8 \%)$ & $0(0 \%)$ & $0(0 \%)$ & $0(0 \%)$ & $36(100 \%)$ \\
\hline \multicolumn{2}{|c|}{ Chi-square test } & 43.27 & & & & & 5.084 & \\
\hline \multicolumn{2}{|l|}{ p-value } & $0.00 \mathrm{I}(\mathrm{H} . \mathrm{S})$ & & & & & $0.07(\mathrm{~S})$ & \\
\hline \multirow{4}{*}{ Brushing } & Once & $20(16.7 \%)$ & $8(6.7 \%)$ & $36(30 \%)$ & $39(32.5 \%)$ & $17(14.2 \%)$ & $20(16.7 \%)$ & $100(83.3 \%)$ \\
\hline & Twice & $9(4.5 \%)$ & $13(6.5 \%)$ & $105(52.5 \%)$ & $45(22.5 \%)$ & $28(\mid 4 \%)$ & $9(4.5 \%)$ & $19 \mid(95.5 \%)$ \\
\hline & $\begin{array}{l}\text { After every } \\
\text { meal }\end{array}$ & $0(0 \%)$ & $0(0 \%)$ & $0(0 \%)$ & $0(0 \%)$ & $0(0 \%)$ & $0(0 \%)$ & $0(0 \%)$ \\
\hline & Don't know & $0(0 \%)$ & $0(0 \%)$ & $0(0 \%)$ & $0(0 \%)$ & $0(0 \%)$ & $0(0 \%)$ & $0(0 \%)$ \\
\hline \multicolumn{2}{|c|}{ Chi-square test } & 23.729 & & & & & 13.47 & \\
\hline \multicolumn{2}{|l|}{ p-value } & $0.001(H . S)$ & & & & & $0.00 \mathrm{I}(\mathrm{H} . \mathrm{S})$ & \\
\hline
\end{tabular}

Table 4 Association of tanita \& organoleptics score for halitosis detection

\begin{tabular}{llllll}
\hline & & Organoleptic score & Chi square test & p-value \\
\cline { 3 - 5 } & & Halitosis Absent & Halitosis present & \\
Tanita & Halitosis Absent & $27(15.7 \%)$ & $145(84.3 \%)$ & 7.36 & $0.007(\mathrm{H} . \mathrm{S})$ \\
\hline
\end{tabular}

Table 5 Sensitivity \& Specificity of organoleptics \& tanita score for diagnosis of halitosis

\begin{tabular}{lllll}
\hline & & \multicolumn{2}{c}{ Organoleptic score } & \\
\cline { 3 - 4 } & & Present & Absent & \\
\hline $\begin{array}{l}\text { Tanita } \\
\text { Score }\end{array}$ & Present & 139 & 9 & $41.4 \%$ \\
Specificity & Absent & 145 & 27 & \\
\hline
\end{tabular}


Table 6 Validity \& Reliability of organoleptics score \& tanita score in the measurement of halitosis

\section{Organoleptics score}

Tanita

Test Inference

Chronbach's alpha

0.24

Moderate agreement

Table 7 Distribution of halitosis patient with gender

\begin{tabular}{lllll}
\hline & Mean \pm S.D & Median & $\begin{array}{l}\text { Mann Whitney } \\
\text { 'U' test }\end{array}$ & P-value \\
\hline Male & $2.17 \pm 1.05$ & 2 & & \\
Female & $2.48 \pm 1.09$ & 2 & 2.739 & 0.006
\end{tabular}

\section{Discussion}

The current cross sectional study, was conducted among halitosis patient to validate organoleptics score and instrumental measurement (i.e. TANITA) in Department of public health Dentistry, Peoples Dental Academy, Bhopal.

The human nose remains the "Gold Standard" in detecting oral halitosis. The most widely used scoring system for ranking halitosis is the Organoleptic Score popularized by Rosenberg \& McCulloch. The organoleptic measurement depends on a trained examiner that has demonstrated reliability in smelling halitosis. The study by Haas et $\boldsymbol{a l} .{ }^{10}$ has demonstrated good levels of reproducibility of breath odor measurements, under a blind evaluation. The reason by which the organoleptic score has been the gold standard for breath measurements rely on the fact that the human nose is capable of smelling and defining as pleasant/unpleasant not only the VSC, but also other organic compounds that come from exhalation and are identified as unpleasant Oral malodor seems to affect a large percentage of population and has multifactorial etiology (biological, dental, psychopathological). Velasco $^{11}$ in his study found sex distribution of $61 \%$ and $47 \%$ were female \& male participants. In prsesnt study, Organoleptic intensity scale found self reported halitosis was $29.70 \%$. Settineri et al. ${ }^{12}$ found rate of self-reported halitosis was $19.39 \%$ and this revealed personal awareness of one's own bad breath.

Study conducted by the Rosenberg et al., ${ }^{9}$ Rosenberg et al., Rosenberg \& McCulloch, ${ }^{9}$ Rosenberg, ${ }^{9}$ Seemann ${ }^{17}$ noticed that Organoleptic oral odor assessments are often not reproducible, as they depend on the subjective judgement of the examiner. Similar type of result was obtained in present study. To avoid interexaminer differences, all measurements in the present study were conducted by the same dentist.

Filippi et al. ${ }^{13}$ conducted a study to assess the halitosis in this study they were concluded that oraganoleptics score among male patient is $46.5 \%$ \& were severe malodor. Similar type of result obtained in present study was $53.6 \%$ were malodor. Miyazaki et al. ${ }^{14}$ conducted a study to asses halitosis in this study it was reveals that prevalence of moderate halitosis was $28 \%$ by using halimeter similar as compared to present study by using TANITA.

Loesche et al. ${ }^{15}$ conducted a study to asses halitosis in this study it was reveals that prevalence of self perception was $31 \%$ \& prevalence of halitosis informed by other $24 \%$. Similarly, Bornstein et al. ${ }^{16}$ reveals that prevalence of organoleptic score was $11.5 \%$ type of present study was done by using organoleptics score the prevalence of halitosis was $89.45 \%$

In present study organoleptic score with severe halitosis is maximum in male i.e $44.4 \%$ \& female $55.6 \%$. Similarly study done by Lovely et al. ${ }^{17}$ reported that $20.9 \%$ were male $\& 3.57 \%$ were female had halitosis. In present study sensitivity \& specificity of organoleptics score \& TANITA was $41.4 \%$ \& $53.3 \%$ respectively. In contrast to study conducted by Maryam et al. ${ }^{18}$ to assess oral malodor. The Sensitivity and specificity was $61.1 \%$ and $87.8 \%$ respectively. Which is greater as compared a to present study.

\section{Conclusion}

Halitosis is a common unpleasant situation that affects individual's life. Halitosis is a crippling social problem. Surprisingly, a problem of this magnitude has been neglected by dental professionals, even though the most common cause is related to microbiota of oral cavity. Several methods are available in the market for the measurement of halitosis but more than an objective assessment, halitosis is a subjective perception of people. Halitosis emerging from intraoral causes can be easily and effectively treated with the use of daily oral hygiene maintenance aids, but halitosis of extraoral origin needs to be explored further and hence treated as of utmost importance. Hence, although halitosis may be a sign or symptom not seemingly needing any immediate care, the wider implications that halitosis has warrants its treatment at a priority basis.

\section{Funding}

None.

\section{Acknowledgments}

None.

\section{Conflicts of interest}

Authors declare that there is no conflict of interest.

\section{References}

1. Nitika jain et.al Oral hygieneawareness and practice among patients attending OPD at Vyas Dental College and Hospital, Jodhpur. Journal of Indian Society of Periodontology. 2012;16(4):524-528.

2. Butt AM. Oral health related quality of life in complete dentures. Pakistan Oral Dental Journal. 2009;29:397-402.

3. WHO Health: Action plan for promotion and integrated disease prevention. New York: World Health Organization; 2006.

4. Parveen M. Oro Dental Health: Awareness and Practices. J Univ Med Dent Coll. 2011;2(2):5-11.

5. Shah N. Geriatric oral health issues in India. Int Dent J. 2001;51(3 Suppl):212-218.

6. Mathew John, Vandana KL. Detection and measurement of oral malodour in periodontitis patients. Ind J Dent Res. 2006;17(1):2-6.

7. Tonzetich J. Production and origin of oral malodour : A review of mechanisms and methods of analysis. J Periodontol.1994;48(1):13-20.

8. Solis-Gaffar MC, Niles HP, Rainieri WC, et al. Instrumental evaluation of mouth odour in a human clinical study. J Dent Res. 1975;54(2): 351-357. 
9. Rosenberg M, McCulloch CA. Measurement of oral malodor: current methods and future prospects. J Periodontol. 1992;63(9):776-782.

10. Hass m, Wang HL. Association between oral malodour and adult periodontitis: a review. J Clin Periodontol. 2001;28(9):813-819.

11. Vlasco E, Bullon P. Periodontal status and treatment needs among spanish hospitalized psychiatric patients. Spec Care Dentist. 1999;19(6):254258 .

12. Settineri S, Carmela M, Simona G, et al. Selfreported halitosis and emotional state: impact on oral conditions and treatments. Health Qual Life Outcomes. 2010;8:34-39.

13. Flippi M, Dadamio J, van den Velde S, et al. Characteristics of 2000 patients who visited a halitosis clinic. J Clin Periodontol. 2009;36(11):970-975.

14. Miyazaki H. Correlation between volatile sulphur compounds \& certain oral health measurements in the general population. $J$ Periodontal.1995;66(8):679-684.
15. Loesche. Bad breath:a multidisciplinary approach, leuven: leuven university press;1996:181-194.

16. Bornstein. Prevalence of halitosis In the population of the city of bern, Switzerland: a study comparing self reported \& clinical data Eur. J Oral science. 2009;117(3):261-267.

17. Lovely M, Stocker BL, Seemann R, et al. Prevalence of halitosis in young male adults: a study in swiss army recruits comparing self-reported and clinical data. J Periodontal. 2009;80(1):24-31.

18. Maryam A, Alkhabuli J, Malik A. The prevalence of self-reported halitosis and oral hygiene practices among Libyan students and office workers. Libyan J Med. 2008;3(4):170-176. 